\title{
O PRINCÍPIO DO POLUIDOR PAGADOR E OS MECANISMOS DE FLEXIBILIZAÇÃO NO PROTOCOLO DE KYOTO
}

\author{
Stefania Eugenia Barichello \\ Luiz Ernani Bonesso de Araujo
}

\section{RESUMO}

O mundo se prepara para grandes investimentos nos países em desenvolvimento e estão sendo criados diversos projetos envolvendo 0 biocombustível, o reflorestamento, que estão gerando lucro para esses países. Assim, a realização de atividades dentro do procedimento de Mecanismo de Desenvolvimento Limpo (MDL) é um instrumento de impulso para atração de investimento internacional e transferência de tecnologia dos países desenvolvimentos para os países não, bem como a melhoria da gestão ambiental em atividades produtivas. $O$ artigo divide-se em três partes. A primeira aborda a Convenção Quadro das Nações Unidas sobre Mudanças Climáticas, a segunda estuda o Protocolo de Kyoto e a terceira o princípio do Poluidor-Pagador e os Mecanismos de Flexibilização.

Palavras-Chave: Mecanismo de desenvolvimento limpo e Protocolo de Kyoto. Princípio do Poluidor Pagador.

\section{INTRODUÇÃO}

Firmado em 1997, o Protocolo de Kyoto tem como aspecto mais relevante a fixação e a imposição de limites quantitativos para as emissões de gases que contribuem com o Efeito Estufa dos países industrializados. Através desse Protocolo os países desenvolvidos, que ratificaram o acordo, assumiram um compromisso legal e vincular de reduzir suas emissões de gases causadores do Efeito Estufa numa média de 5,2\% com respeito aos níveis de emissões do ano 1990 . Esta redução de emissões deve realizar-se no período 2008-2012 ao finalizar o chamado "Primeiro período de compromisso".

Os países ratificantes do Protocolo de Kyoto se denominam Partes e se agrupam segundo seu grau de desenvolvimento como países Anexo I e países não Anexo I. O primeiro grupo é integrado por países desenvolvidos que adotaram compromissos de redução de gases que contribuem com o Efeito Estufa, e o segundo por países em desenvolvimento que, por esse motivo, não assumiram obrigações de diminuição de emissões, mas que contribuem com o objetivo do Protocolo através da acolhida em seus territórios de atividades que reduzam e/ou absorvam quantidades de gases causadores do Efeito Estufa na atmosfera.

Considerando que a industrialização dos países desenvolvidos foi a maior responsável pela poluição até os dias atuais, ficou acordado que essas nações 
deveriam ser responsáveis pela redução. Entretanto, foram criadas flexibilizações, através das quais os países ricos podem promover a redução fora do seu território.

Com caráter suplementar às políticas nacionais de redução de emissões de gases causadores do Efeito Estufa, o Protocolo de Kyoto introduz três mecanismos cujo objetivo principal é oferecer às Partes meios para diminuir as emissões com menos gastos no exterior que no próprio país, promovendo o desenvolvimento de um mercado global de comercialização de permissões e/ou créditos de carbono.

Exatamente a partir desses aspectos se evidencia a necessidade de assegurar que o crescimento econômico venha acompanhado da devida proteção ao meio ambiente, combinando as aspirações compartilhadas por todos os países, em relação ao progresso econômico e material, com a necessidade de uma consciência ecológica.

O objetivo desse artigo é analisar se o os mecanismos de flexibilização previstos no Protocolo de Kyoto refletem o Princípio do Poluidor-Pagador. 0 artigo divide-se em três partes. A primeira abordará a Convenção Quadro das Nações Unidas sobre Mudanças Climáticas; a segunda, o Protocolo de Kyoto bem como seus principais objetivos e os mecanismos de flexibilização previstos no protocolo; e na terceira será exposta uma breve revisão bibliográfica acerca do princípio do poluidor-pagador, para que, por fim, seja possível analisar os mecanismos de flexibilização na lógica do princípio do poluidor-pagador.

\section{A CONVENÇÃO QUADRO DAS NAÇÕES UNIDAS SOBRE MUDANÇAS CLIMÁTICAS}

A preocupação com o clima do planeta teve início na década de 80 , tendo como um dos fatores de incentivo o sucesso do Protocolo de Montreal, por meio do qual os países membros se comprometeram com a redução gradual até a substituição total do uso do gás clorofluorcarbono (CFC), responsável pela crescente destruição da camada de ozônio.

Em 1990, o Painel Intergovernamental sobre Mudança Climática (IPCC), formado por membros do corpo científico da Organização das Nações Unidas, elaborou um relatório que alertava para o fato de que a ação humana poderia estar causando o Efeito Estufa. Desde então, foram iniciadas as negociações para a adoção do que viria a ser a primeira Convenção Quadro das Nações Unidas sobre Mudanças Climáticas (UNFCCC, United Nations Framework Climate Change Convention), ocorrida em 1992, onde emergia a preocupação dos líderes mundiais com as alterações no clima, assim como da necessidade de ações mais enérgicas no futuro a respeito dos gases causadores do efeito estufa. No mesmo ano, na ECO RIO 92, foram abertas às assinaturas e ratificação ${ }^{3}$.

A Convenção entrou em vigor em 21 de março de 1994, 90 dias após a qüinquagésima ratificação. $O$ Brasil foi o primeiro país que assinou a ConvençãoQuadro das Nações Unidas para Mudança do Clima, em 4 de junho de 1992, durante a ECO RIO 92 e o Congresso Nacional a ratificou em 28 de fevereiro de 1994. A Convenção conta hoje com 186 países signatários. 
Os países estão divididos em 2 grupos pelas diferenças econômicas, sociais e de desenvolvimento. Dentro do Anexo I da Convenção estão dispostos os países desenvolvidos e também alguns países com Economia em transição como a Federação Russa e a Europa Oriental. "As partes do Anexo I ainda foram subdivididas em Anexo II, que são 24 países que apresentam melhores condições econômicas e maior potencial de emissão de gases causadores do efeito estufa'4. 0 restante dos países, em sua maioria países em desenvolvimento, fazem parte do Não Anexo I, termo adotado pela doutrina por não haver um anexo que trate especificamente desses países.

\title{
Conforme NUSDEO, essa convenção é considerada
}

\begin{abstract}
um tratado-quadro, pois contém normas genéricas voltadas à redução da emissão de dióxido de carbono e de outros gases que provocam o efeito estufa, mas sem definir com precisão as obrigações de redução de emissões pelos diferentes países, o que deve ser levado a efeito por tratados posteriores firmados pelas mesmas partes. (...) A convençãoQuadro criou, como órgão da convenção, a Conferência das Partes, formada pelos países signatários, que deveria reunir-se periodicamente para elaborar estratégias mais específicas para a redução das emissões danosas ao meio ambiente ${ }^{5}$.
\end{abstract}

Como resultado de uma dessas Conferências, foi realizado em Kyoto no Japão, em 1997, a $3^{\text {a }}$ Conferência das Partes da Convenção Quadro das Nações Unidas sobre Mudança do Clima, chamado de Protocolo de Kyoto.

\section{PROTOCOLO DE KYOTO}

A Convenção-Quadro é uma convenção inespecífica, que trata de muitos assuntos ao mesmo tempo, não dando ênfase especial a nenhum deles. Nesse contexto encontra-se a importância do Protocolo de Kyoto que veio regulamentar e especificar a Convenção. Apesar de funcionar como um "apêndice" à Convenção, o Protocolo tem regras próprias além das compartilhadas e prevê sanções aos infratores, as quais fazem com que a Convenção ganhe eficácia e efetividade ${ }^{6}$. 0 Protocolo de Kyoto é um tratado acessório à Convenção Quadro das Nações Unidas sobre Mudança do Clima e as partes do Protocolo devem ser Partes desta Convenção.

Naquele encontro estiveram presentes representantes de 39 países desenvolvidos, cuja tarefa seria de elaborar metas e prazos referentes à redução ou limitação das emissões futuras de dióxido de carbono e outros gases responsáveis pelo Efeito Estufa, provenientes do desequilíbrio radioativo da Terra e que provocam alteração das temperaturas atmosféricas e oceânicas bem como do ciclo hidrológico.

Quanto ao efeito estufa, José Afonso da Silva ensina que:

o efeito estufa natural mantém a atmosfera em torno de $30^{\circ} \mathrm{C}$ mais aquecida, possibilitando a vida no Planeta, sem o qual seria impossível. Mas o aumento artificial, por ação humana, com emissões adicionais de gases de efeito estufa, especialmente o já mencionado dióxido de carbono, gera aquecimento adicional com efeitos que podem ser catastróficos para a Humanidade, como, por exemplo, o aumento do nível do mar ${ }^{7}$. 
Os objetivos do Protocolo são a diminuição das emissões os gases causadores do efeito estufa e a sua maior absorção pelos sumidouros naturais, promovendo prazos e metas específicas para as Partes. "As medidas vinculantes e flexibilizadoras atuam no duplo sentido de pressionar o cumprimento das metas e incentivar um meio mais prático e barato de se chegar a elas",

Os países do Anexo I da Convenção-Quadro assumiram diferentes metas percentuais, e poderão utilizar-se de "mecanismos flexíveis", que servirão também para abater as metas de carbono absorvidas nos chamados "sorvedouros", tais como florestas e terras agrícolas. Estão previstas penalidades para os países que não conseguirem cumprir a sua parte na meta. Uma das principais medidas para se atingir o resultado esperado na forma concebida, seria a de investir em formas alternativas de produção de energia.

Os países em desenvolvimento, dentre eles o Brasil, também passaram a
fazer parte do Protocolo e, como os países desenvolvidos, também teriam
que nivelar a poluição do ar em seus territórios. Os países
subdesenvolvidos receavam que as medidas que deveriam ser tomadas
para controlar a poluição do ar atingissem ou prejudicassem o seu
crescimento econômico e estagnassem suas economias. Contudo, foram
observadas corretamente as diferenças históricas e tecnológicas dos
países, só sendo adotados mecanismos vinculantes de redução de
emissões para os países desenvolvidos. ${ }^{9}$

Composto por 28 artigos e dois anexos. O Anexo A traz a lista dos Gases de efeito estufa e os setores onde estes podem ser encontrados e o Anexo B traz os países com Compromisso de redução ou limitação quantificada de emissões.

\title{
2.1 Mecanismos de flexibilização
}

O Protocolo de Kyoto estabelece, ainda, 3 tipos "mecanismos de flexibilização" com intuito de

\begin{abstract}
viabilizar o alcance das metas de redução de emissões e complementar os esforços realizados por cada Parte para a redução e eliminação de gases em seu território. Esses mecanismos consistem em projetos suplementares às ações domésticas, objetivando $o$ alcance das metas estabelecidas $\mathrm{e} o$ cumprimento dos compromissos assumidos no âmbito do Protocolo ${ }^{10}$.
\end{abstract}

Dentre esses 3 mecanismos "criados para facilitar o cumprimento das metas pelos países desenvolvidos" encontramos os seguintes:

- Mecanismo de Implementação Conjunta (Joint Implementation): tal mecanismo permite aos países Anexo I executar projetos que reduzam as emissões ou consigam uma maior absorção utilizando sumidouros, em outros países Anexo I. As unidades de redução de emissões (ERU) geradas por estes projetos podem ser utilizados pelas Partes investidoras do Anexo I para ajudar a cumprir seus objetivos de emissão. Os projetos de IC devem contar com a aprovação de todas as Partes envolvidas para dar lugar às reduções e absorções de emissões que sejam adicionais às que se teriam registrado em sua ausência.

- Mercado Internacional das Emissões (International Emissions Trading): através desse regime os países do Anexo I e/ou suas empresas podem 
comercializar livremente unidades de suas quantidades atribuídas que Ihes foram atribuídas de conformidade com seus níveis de emissões de gases causadores do efeito estufa e de acordo com os termos do Protocolo. Este sistema permite às Partes Anexo I adquirir unidades de suas quantidades atribuídas daqueles setores que contem com excedentes das mesmas por ter-lhes resultado mais fácil e econômico diminuir as quantidades de gases causadores do efeito estufa que enviam à atmosfera em suas atividades e/ou processos produtivos.

- Mecanismo para um Desenvolvimento Limpo - MDL (Clean Development Mechanism): através desse mecanismo torna-se possível a realização de projetos de redução e/ou absorção de emissões de gases causadores do efeito estufa em países não Anexo I em troca de reduções de emissões certificadas (CER). Os CER derivados desses projetos podem ser comercializados livremente e serão finalmente utilizados pelas Partes do Anexo I para dar cumprimento às obrigações assumidas em Kyoto. Os projetos MDL devem contribuir ao desenvolvimento sustentável e dar lugar a benefícios reais, mensuráveis e duradouros para o clima, em forma de redução e/ou absorção de emissões de gases causadores do efeito estufa, adicionais às que se teriam produzido sem o projeto.

O compromisso mais expressivo do Protocolo encontra-se no artigo 3.1, onde

as Partes incluídas no Anexo I devem, individual ou conjuntamente, assegurar que suas emissões antrópicas agregadas, expressas em dióxido de carbono equivalente, dos gases de efeito estufa listados no Anexo A não excedam suas quantidades atribuídas, calculadas em conformidade com seus compromissos quantificados de limitação e redução de emissões descritos no Anexo B e de acordo com as disposições desse artigo, com vista a reduzir suas emissões totais desses gases em pelo menos $5 \%$ abaixo dos níveis de 1990 no período de compromisso de 2008 a $2012^{11}$

Quanto ao Brasil e os demais países em desenvolvimento não incluídos no Anexo B do Protocolo (como China, Índia e México), esses ainda não estão obrigados a reduzir suas emissões de dióxido de carbono, não tendo de se comprometer com metas específicas. Como signatários, no entanto, eles precisam manter a ONU informada do seu nível de emissões e buscar o desenvolvimento de estratégias para as mudanças climáticas. Porém, é muito provável que quando se iniciar a segunda fase do Protocolo de Kyoto, em 2012, países como o Brasil, China e Índia venham a ser obrigados a reduzir suas emissões de gases causadores do efeito estufa.

\section{PRINCÍPIO DO POLUIDOR PAGADOR E OS MECANISMOS DE FLEXIBILIZAÇÃO DO PROTOCOLO DE KYOTO}

De maneira geral, pode-se dizer que princípio é algo que se deve admitir como pressuposto e aflora de modo expresso em múltiplas e diferentes normas. São linhas diretrizes que informam algumas normas e inspiram direta ou indiretamente uma série de soluções, promovem e embasam a aprovação de normas, orientam a interpretação das existentes.

Os princípios que norteiam o Direito Ambiental têm suas origens nas Conferências de Estocolmo e do Rio e nos respectivos direitos internos dos países, tendo em vista suas peculiaridades. $O$ direito intemo brasileiro seguiu a mesma 
lógica, uma vez que o legislador pátrio vai construir normas ambientais relevantes, características, sistematizadas, principalmente depois da primeira Conferência Mundial sobre o meio ambiente humano, ocorrida em 1972.

Para Cristiane Derani, os princípios ambientais são "construções teóricas que visam a melhor orientar a formação do Direito Ambiental, procurando denotar-Ihe uma certa lógica de desenvolvimento, uma base comum nos instrumentos normativos" ${ }^{12}$ de política ambiental.

O princípio do poluidor-pagador decorre do $16^{\circ}$ princípio instituído pela Declaração do Rio, o qual enfatiza que

as autoridades nacionais devem procurar promover a internacionalização dos custos ambientais e o uso de instrumentos econômicos, tendo em vista a abordagem segundo a qual o poluidor deve, em princípio, arcar com o custo da poluição, com a devida atenção ao interesse público e sem provocar distorções no comércio e nos investimentos internacionais.

$O$ poluidor tem que arcar com o ônus dos danos de sua atividade. 0 que se quer é a prevenção, a precaução, o cuidado prévio (e aqui, cabe ao potencial poluidor custeá-los). No entanto, ocorrida a degradação e a poluição, cabe ao poluidor pagar tal reparação. Como o princípio enuncia não se deve inferir que se paga para poluir. Assim, o poluidor deve não só pagar, mas reparar o dano. Visa sinteticamente à internalização dos custos externos de deterioração ambiental.

Portanto, o princípio do poluidor pagador tem por objetivo internalizar os custos das externalidades ${ }^{13}$ negativas advindas do uso dos bens ambientais. Assim, o agente econômico que causar o dano ambiental diante de sua atividade, seja na produção, consumo ou no transporte, deverá arcar com os custos da poluição produzida.

O Princípio do Poluidor Pagador implica em atribuir ao poluidor os ônus anteriores e posteriores ao desenvolvimento da atividade, ou seja, refere-se à internalização dos custos de prevenção e precaução, bem como de responsabilização pelos danos. Cabe ao poluidor, e não ao Estado (e, conseqüentemente, a sociedade como um todo), arcar com todos os custos de prevenção, precaução e reparação dos danos ambientais:

O princípio poluidor-pagador não é um princípio de compensação dos danos causados pela poluição. Seu alcance é mais amplo, incluindo todos os custos da proteção ambiental, quaisquer que sejam eles, abarcando, ao nosso ver, os custos de prevenção, de reparação e de repressão do dano ambiental assim como aqueles outros relacionados com a própria utilização dos recursos ambientais, particularmente os naturais ${ }^{14}$. (BENJAMIN, 1993, p. 231).

Tal princípio não pode ser confundido como direito de poder poluir. Regina Helena Costa defende que "a compreensão universal de tal princípio, no sentido de que o mesmo não conduz a afirmação do 'direito de poluir', traduzido no pensamento 'quem paga pode poluir', mesmo porque o meio ambiente é um conjunto de valores economicamente inestimáveis"'15. 
Está previsto no texto constitucional, no $\$ 3^{\circ}$, do art. 225 , o qual dispõe que "as condutas e atividades consideradas lesivas ao meio ambiente sujeitarão os infratores, pessoas físicas ou jurídicas, a sanções penais e administrativas, independentemente da obrigação de reparar os danos causados".

José Marcos Domingues de Oliveira esclarece, em sua obra, as formas jurídicas de se aplicar o princípio do poluidor pagador: "Juridicamente, o princípio do poluidor-pagador pode realizar-se tanto através do licenciamento administrativo, da imposição de multas, da determinação de limpeza ou recuperação ambiental, como pela cobrança de tributos, enquanto fonte de recursos para custeio da proteção ambiental'"16.

Modé salienta que

o princípio do poluidor pagador, embora possa ser enunciado como princípio que impõe ao causador de um dano ambiental a sua reparação (Princípio 16 da Declaração do Rio/92), a isso não se limita. (....) O poluidor pagador e o usuário pagador: ao primeiro recairiam os custos da prevenção da poluição e da eventual recuperação de um dano causado, enquanto o segundo suportaria o custo efetivo de um recurso natural em face de sua escassez ${ }^{17}$.

Torna-se pertinente esclarecer que,

não obstante essa formulação impositiva do princípio do poluidor-pagador, de imputação ao poluidor do rateio de custo das ações estatais necessárias à preservação e recuperação ambientais, há que se descortinar um sentido seletivo do princípio determinante da graduação da tributação, de forma a incentivar atividades não-poluidoras e desestimular aquelas nefastas à preservação ambiental $^{18}$.

Conforme se pode observar no texto supra citado, esse princípio caracterizase por duas faces. Essa primeira face, impositiva, impõe o dever do Estado de cobrar do poluidor contribuições em função de sua atividade poluidora, de forma a fazê-lo arcar com o custo dos serviços públicos gerais ou específicos necessários à preservação e recuperação do meio ambiente. Em seu aspecto econômico, portanto, o princípio do poluidor pagador visa à indenização dos custos externos da degradação ambiental devendo, portanto, ser articulado com os princípios da precaução, prevenção e responsabilização.

Nesse aspecto Leite e Ayala salientam que "a essência desse princípio é eminentemente preventiva, pelo que podemos afirmar que comporta uma tríplice dimensão, que é primeiramente preventiva, para admitir também, posteriormente, a reparação e a repressão como ultima ratio (solução ressarcitória), ${ }^{, 19}$.

Olivier Godard defende a aplicação dos mecanismos flexibilizadores, argumentando que apenas com esta compensação econômica será possível implementar políticas públicas com alto custo social ${ }^{20}$. Dessa forma, a criação do mercado de carbono teria o importante papel de facilitar o cumprimento dos objetivos dos tratados que expressam a necessidade de se tomar medidas para conter o aquecimento global. 
Entendemos que os mecanismos flexíveis não afrontam o princípio do poluidor pagador, pois representam meios suplementares pelos quais os Estados signatários podem cumprir suas metas de forma global a um custo mais baixo. Tampouco entendemos que estes mecanismos sejam uma permissão para poluir, desde que se mantenham como suplementares em relação às políticas públicas. $O$ estímulo econômico se justifica pelo fato das emissões GEE serem globais, não importando tanto para efeitos da mitigação das mudanças climáticas aonde elas sejam reduzidas ${ }^{21}$.

Quanto ao mecanismo de desenvolvimento limpo, diversos autores ensinam que esse exprime a lógica do princípio do poluidor-pagador, pois prevê que os países desenvolvidos internalizem o custo da emissão dos gases do efeito estufa na atmosfera, financiando projetos de captura de gases em países em desenvolvimento. Impedindo a socialização dos prejuízos no âmbito internacional pois, embora o aquecimento global represente um problema para todos, as alterações climáticas são ocasionadas por atividades humanas em decorrência da degradação ambiental desordenada e sem qualquer tipo de planejamento ou preservação principalmente advindos do estilo de vida adotado por habitantes dos países ditos desenvolvidos. ${ }^{22}$

Entretanto, para os críticos do Protocolo de Kyoto, os mecanismos, ao flexibilizarem as obrigações, refletem os interesses de valorar economicamente os gases tomando-os, de acordo com a lógica capitalista, objetos de troca. Afirma, a respeito da criação do mercado de carbono, Monique Chemillier-Gendreau:

A proteção da natureza não é negociável. Aplicar a ela a lógica mercantilista (do mercado) é arruiná-la. É verdade que o limite entre a esfera do mercado e aquela do interesse geral está em vias de desaparecer nas sociedades em que as fronteiras se apagam sob o efeito da globalização mas, de fato, o nível mundial é o único pertinente para reinventar o interesse geral, e dizer aquilo que deve por natureza "escapar" do negócio, o qual é sempre um compromisso. A proteção da humanidade e de suas condições de sobrevivência é um absoluto sobre os quais nenhuma transação é admissível. Não há outro meio para assegurar a igualdade dos humanos em relação ao (frente ao) clima e fixar equitativamente as emissões que tomam por base de cálculo o número de habitantes. Se certos Estados não emitirem as quantidades permitidas ou reduzirem-nas mais rapidamente que o previsto, é uma chance para o equilíbrio climático, e não um excedente que os mais vorazes podem consumir. ${ }^{23}$

Com isso, a internalização dos custos ambientais (no caso a emissão dos gases do efeito estufa) seria uma resposta insuficiente ao problema do aquecimento global, visto que as modestas metas do Protocolo de Kyoto não terão qualquer efeito enquanto continuarmos (em especial os países que mais emitem os gases do efeito estufa) a perseguir e reproduzir um estilo de vida baseado no consumo desenfreado de energia, isso é, a produzir e desejar carros individuais, aquecimento de inverno não eficientes para todos os ambientes das casas, produtos industrializados em abundância, alimentação ultra-carnívora, etc. Afirmam, nesse sentido, Le Treut e Jancovici:

Na França, este consumo decorre de alguns usos de importância relativamente equivalente: deslocar-se, aquecer-se, consumir produtos manufaturados e, num certo sentido, comer. $O$ modo de vida que nós escolhemos caracteriza-se antes de tudo por certos pré-requisitos: espaço habitável, velocidade de deslocamento, distância entre o domicílio e o local 
de trabalho, quantidade de carne consumida, etc. Cada uso implica um consumo mínimo de energia que a melhor das tecnologias não poderá jamais reduzir ${ }^{24}$.

\section{CONCLUSÃO}

As mudanças climáticas são um problema de ação coletiva. Ambos, Protocolo de Kyoto e Estado Nacional, são apenas partes da solução. A constituição do todo depende do engajamento da sociedade. É bom lembrar que a emissão de poluentes não se restringe apenas aos grandes setores produtivos (agricultura, indústria e comércio), mas também ao uso ineficiente e/ou ao desperdício que se cometem no dia-a-dia ao utilizar automóveis, eletrodomésticos, etc., ou seja, ao se consumir energia. Portanto, a consciência de todos é também prioritária para garantir o futuro das próximas gerações!

O mundo desenvolvido tem feito grandes investimentos nos países em desenvolvimento e estão sendo efetivados diversos projetos envolvendo o biocombustível, o reflorestamento, os aterros sanitários, entre outros, que estão gerando lucro para esses países. Nesse sentido, a realização de atividades dentro do procedimento de Mecanismo de Desenvolvimento Limpo (MDL) é um instrumento de impulso para atração de investimento internacional e transferência de tecnologia dos países desenvolvimentos para os países em desenvolvimento, bem como a melhoria da gestão ambiental em atividades produtivas.

É possível interpretar o princípio do poluidor-pagador de forma que este rompa com a lógica economicista de que o pagador pode poluir, e que comporte $o$ caráter prevenção, precaução e reparação ${ }^{25}$.

Não está presente, porém, no mecanismo de desenvolvimento limpo este sentido ampliado que indique a intenção de uma ruptura com os padrões de produção e consumo responsáveis pela alteração climática, mas tão-somente a possibilidade de comprar o direito de poluir no lucrativo mercado de carbono ${ }^{26}$.

Uma maior aplicação do princípio do poluidor-pagador, vital para o enfrentamento das mudanças climáticas, exige políticas públicas que utilizem instrumentos normativos (filtros industriais obrigatórios, desapropriação para fins de reflorestamento, etc.) e econômicos (taxas e impostos sobre emissões de GEE), além de mercados de permissões regulados de maneira eficaz pelo Estado, com previsões de multas e taxas para as emissões excedentes. A insuficiência dos mecanismos de mercado clama pela adoção urgente e imediata dessas políticas.

\section{THE POLLUTE PAYER PRINCIPLE AND THE LESSENING MECHANISMS ON KYOTO'S PROTOCOL}

\section{ABSTRACT}

The developed world prepares for great investments in the developing countries and is being developed diverse projects involving biofuel, reforestation, that are generating profit for these countries. Thus, the accomplishment of activities 
inside of the procedure of Clean Development Mechanism is an instrument of impulse for attraction of international investment and technologies transfer of the countries developments for countries Non-Annex I, as well as the improvement of the ambient management in productive activities. The article is divided in three parts. The first one, approaches the United Nations Framework Convention on Climate Change, second it studies the Kyoto Protocol of and the third the polluter-pays principle and flexibility mechanisms.

Principle.

Keywords: Clean Development Mechanism and Kyoto Protocol. Polluter Pays NOTAS

Aluna do Master Mercosur ed Unione Europea a confronto da Università degli studi di Udine, Itália, e do Mestrado em Integração Latino-Americana da Universidade Federal de Santa Maria. Especialista em Direito Empresarial pela Universidade Federal do Rio Grande do Sul.

2 Doutor em Direito pela Universidade Federal de Santa Catarina Professor da Universidade Federal de Santa Maria, da Universidade de Santa Cruz do Sul.

3 CALSING, Renata de Assis. O Protocolo de Quioto e o Direito do desenvolvimento sustentável. Porto Alegre: Sérgio Antônio Fabris, 2005.

4 CALSING, Renata de Assis. O Protocolo de Quioto e o Direito do desenvolvimento sustentável. Porto Alegre: Sérgio Antônio Fabris, 2005, p. 43.

5 NUSDEO, Ana Maria de Oliveira. Desenvolvimento sustentável do Brasil e o protocolo de Kyoto. Revista de Direito Ambiental, São Paulo, v. 37, p. 144-159, 2005, p. 150.

6 SOARES, Guido Fernando Silva. A proteção internacional do meio ambiente. Barueri: Manole, 2003

7 SILVA, José Afonso da. Direito Ambiental Constitucional. São Paulo: Malheiros Editores, 2004, p. 67.

8 CALSING, Renata de Assis. O Protocolo de Quioto e o Direito do desenvolvimento sustentável. Porto Alegre: Sérgio Antônio Fabris, 2005, p. 77.

9 CALSING, Renata de Assis. O Protocolo de Quioto e o Direito do desenvolvimento sustentável. Porto Alegre: Sérgio Antônio Fabris, 2005, p.75-76

10 BARCELLOS, Ricardo Dornelles Chaves; AMARAL, Renata Campetti. Protocolo de Kyoto - O mercado a favor da conservação ambiental. In: TIMM, Luciano Benetti (org.). Direito e economia. São Paulo: IOB Thomson, 2005. p.185-197, p.67.

11 SILVA, José Afonso da. Direito Ambiental Constitucional. São Paulo: Malheiros Editores, 2004, p. 67.

12 DERANI, Cristiane. Direito Ambiental Econômico. São Paulo: Max Limonad, 1997, p. 155.

13 São identificadas pela Ciência Econômica como externalidades os efeitos externos não assimilados pelo sistema de preços produzidos pelas atividades humanas, sobretudo as socioeconômicas, que repercutem sobre consumidores e produtores (IRIGARAY, 2004, p. 58). BENJAMIN, Antonio Herman V., O Princípio Poluidor-Pagador e a reparação do dano ambiental. In: BENJAMIN, Antonio Herman V. (Cord.). Dano ambiental: prevenção, reparação e repressão. São Paulo: Revista dos Tribunais, 1993, P. 231.

15 COSTA, Regina Helena. Tributação Ambiental. In: FREITAS, Vladimir Passos de (org). Direito Ambiental em Evolução. Curitiba: Juruá, 1998. p.297-309, p. 299. OLIVEIRA, José Marcos Domingues de. Direito Tributário e Meio Ambiente: proporcionalidade, tipicidade aberta, afetação da receita. Rio de Janeiro: Renovar, 1995, p. 16.

17 MODÉ, Fernando Magalhães. Tributação Ambiental. Curitiba: Juruá, 2003, p. 64.

18 OLIVEIRA, José Marcos Domingues de. Direito Tributário e Meio Ambiente: proporcionalidade, tipicidade aberta, afetação da receita. Rio de Janeiro: Renovar, 1995, p. 18.

19 LEITE, José Rubens Morato; AYALA, Patryck. Direito Ambiental na Sociedade de Risco. Rio de Janeiro: Forense, 2004, p. 80.

20 GODARD, Olivier. Politique de l'effet de serre. Une évaluation du plan français de quotas de CO2. Revue française d'economie, nº, vol. XIX, 2005, p. 147-186. 
AVZARADEL, Pedro Curvello Saavedra. Princípios do Direito Ambiental e Mudanças Climáticas: Uma abordagem a partir da Teoria da Sociedade de Risco. In: Simpósio Dano Ambiental na Sociedade de Risco. 2. 2007. Florianópolis. Anais... Florianópolis, 2007. p. 696-709, p. 706-707. GONÇALVES, Verônica Korber. O Protocolo de Quioto e o Princípio do Poluidor-Pagador. In: Simpósio Dano Ambiental na Sociedade de Risco. 2. 2007. Florianópolis. Anais... Florianópolis, 2007, p. 835-846.

23 Apud GONÇALVES, Verônica Korber. O Protocolo de Quioto e o Princípio do Poluidor-Pagador. In: Simpósio Dano Ambiental na Sociedade de Risco. 2. 2007. Florianópolis. Anais... Florianópolis, 2007, p. 835-846, p. 843.

24 LE TREUT, Hervé; JANCOVICI, Jean-Marc. L'effet de serre. Allons-nous changer le climat? Paris: Flammarion. 2004, p. 167.

25 GONÇALVES, Verônica Korber. O Protocolo de Quioto e o Princípio do Poluidor-Pagador. In: Simpósio Dano Ambiental na Sociedade de Risco. 2. 2007. Florianópolis. Anais... Florianópolis, 2007, p. 835-846, p. 844;

26 GONÇALVES, Verônica Korber. O Protocolo de Quioto e o Princípio do Poluidor-Pagador. In: Simpósio Dano Ambiental na Sociedade de Risco. 2. 2007. Florianópolis. Anais... Florianópolis, 2007, p. 835-846, p. 845.

\section{REFERÊNCIAS}

ARAGÃO, Maria Alexandra de Sousa. O princípio do poluidor pagador: pedra angular na política comunitária do ambiente. In: Boletim da Faculdade de Direito da Universidade de Coimbra. Coimbra: Coimbra Editora, 1997.

AVZARADEL, Pedro Curvello Saavedra. Princípios do Direito Ambiental e Mudanças Climáticas: Uma abordagem a partir da Teoria da Sociedade de Risco. In: Simpósio Dano Ambiental na Sociedade de Risco. 2. 2007. Florianópolis. Anais. Florianópolis, 2007. p. 696-709.

BARCELLOS, Ricardo Dornelles Chaves; AMARAL, Renata Campetti. Protocolo de Kyoto - O mercado a favor da conservação ambiental. In: TIMM, Luciano Benetti (org.). Direito e economia. São Paulo: IOB Thomson, 2005. p.185-197.

BENJAMIN, Antonio Herman V., O Princípio Poluidor-Pagador e a reparação do dano ambiental. In: BENJAMIN, Antonio Herman V. (Cord.). Dano ambiental: prevenção, reparação e repressão. São Paulo: Revista dos Tribunais, 1993.

CALIENDO, Paulo. Tributação e mercado de carbono. In: TÔRRES, Heleno Taveira. Direito Tributário Ambiental. São Paulo: Malheiros Editores, 2005. p. 888.

CALSING, Renata de Assis. $O$ Protocolo de Quioto e o Direito do desenvolvimento sustentável. Porto Alegre: Sérgio Antônio Fabris, 2005.

CHANG, Manyu. Seqüestro de Carbono Florestal: oportunidades e riscos para o Brasil. Revista paranaense de desenvolvimento. Curitiba, n. 102 , p. 85-100, janjun 2002.

CHEMILLIER-GENDREAU, Monique. Marchandisation de la survie planétaire. Le Monde Diplomatique. Janvier 1998.

COSTA, Regina Helena. Tributação Ambiental. In: FREITAS, Vladimir Passos de (org). Direito Ambiental em Evolução. Curitiba: Juruá, 1998. p.297-309. 
DEBONI, Giuliano. Protocolo de Kyoto: boa oportunidade para o Brasil. Jus Navigandi, Teresina, ano 9, n. 609, 9 mar. 2005. Disponível em: <http://jus2.uol.com.br/doutrina/texto.asp?id=6422>. Acesso em: 20 nov. 2006.

DERANI, Cristiane. Direito Ambiental Econômico. São Paulo: Max Limonad, 1997.

DIAS, Edna Cardozo. Mercado de carbono. Fórum de Direito Urbano e Ambiental. Belo Horizonte, ano 5; n. 25, p. 3041-3044, jan-fev 2006.

. Convenção do Clima. Fórum de Direito Urbano e Ambiental. Belo Horizonte, ano 3, n. 13, p. 1335 -1339, jan-fev 2004

DINIZ, Eliezer Martins. Crescimento, poluição e o Protocolo de Quioto. uma avaliação do caso brasileiro. São Paulo: Banco Santos/ Universidade de Oxford, 2001

EGUREN C., Lorenzo. EL mercado de carbono en América Latina y el Caribe: balance e perspectivas. Santiago del Chile: CEPAL, 2004

GODARD, Olivier. Politique de l'effet de serre. Une évaluation du plan français de quotas de CO2. Revue française d'economie, $\mathrm{n}^{\circ} 4$, vol. XIX, 2005, p. 147-186.

GONÇALVES, Verônica Korber. O Protocolo de Quioto e o Princípio do PoluidorPagador. In: Simpósio Dano Ambiental na Sociedade de Risco. 2. 2007.

Florianópolis. Anais. Florianópolis, 2007, p. 835-846.

HONTY, Gerardo. America Latina ante el Cambio Climático. Disponível em:<http://www.energiasur.com/cambioclimatico/ODGlbz4CambioClimaticoHonty.pdf >. Acesso em: 25. mar. 2007.

IRIGARY, Calos Teodoro José Hugueney. 0 emprego de instrumentos Ecoômicos na Gestão Ambiental. In: LEITE, José Rubens Morato; BELLO FILHO, Ney de Barros. Direito Ambiental Contemporâneo. Barueri: Manole, 2004.

LE TREUT, Hervé; JANCOVICI, Jean-Marc. L'effet de serre. Allons-nous changer le climat? Paris: Flammarion. 2004.

LEFF, Enrique. Epistemologia ambiental. São Paulo: Cortez, 2006.

LEITE, José Rubens Morato; AYALA, Patryck. Direito Ambiental na Sociedade de Risco. Rio de Janeiro: Forense, 2004.

MODÉ, Fernando Magalhães. Tributação Ambiental. Curitiba: Juruá, 2003.

NUSDEO, Ana Maria de Oliveira. Desenvolvimento sustentável do Brasil e o protocolo de Kyoto. Revista de Direito Ambiental, São Paulo, v. 37, p. 144-159, 2005. 
OLIVEIRA, José Marcos Domingues de. Direito Tributário e Meio Ambiente: proporcionalidade, tipicidade aberta, afetação da receita. Rio de Janeiro: Renovar, 1995.

SILVA, José Afonso da. Direito Ambiental Constitucional. São Paulo: Malheiros Editores, 2004.

SOARES, Guido Fernando Silva. $A$ proteção internacional do meio ambiente. Barueri: Manole, 2003.

SOLA, Juan Vicente. Constituición y Economia.. 1.ed. Buenos Aires: Abeledo Perrot, 2004.

VARELLA, Marcelo Dias. Direito Internacional Econômico Ambiental. Belo Horizonte: Del Rey, 2004.

VIOLA, Eduardo; LEIS, Héctor Ricardo. Gobernabilidad global posutópica, medio ambiente y cambio climático. Revista Nueva Sociedad. Caracas, n.185, p. 34-49, maio-jun. 2003.

O regime Internacional de Mudança climática e o Brasil. Revista Brasileira de Ciências Sociais. São Paulo, V. 17, n. 50, p. 25-46, out. 2002.

Recebido para publicação 22/04/2009

Aceito para publicação 08/12/2009 